\title{
Prognostic Value of Relevant Clinicopathologic Variables in Epithelioid Sarcoma: A Multi-Institutional Retrospective Study of 44 Patients
}

\author{
Naofumi Asano, $\mathrm{MD}^{1,3}$, Akihiko Yoshida, $\mathrm{MD}, \mathrm{PhD}^{2}$, Koichi Ogura, $\mathrm{MD}^{1}$, Eisuke Kobayashi, MD, $\mathrm{PhD}^{1}$, \\ Michiro Susa, MD, PhD ${ }^{3}$, Hideo Morioka, MD, PhD ${ }^{3}$, Shintaro Iwata, MD, PhD ${ }^{4}$, Takeshi Ishii, MD, PhD ${ }^{4}$, \\ Toru Hiruma, MD, PhD ${ }^{5}$, Hirokazu Chuman, MD, PhD ${ }^{1}$, and Akira Kawai, MD, PhD $^{1}$ \\ ${ }^{1}$ Department of Musculoskeletal Oncology, National Cancer Center Hospital, Tokyo, Japan; ${ }^{2}$ Department of Pathology, \\ National Cancer Center Hospital, Tokyo, Japan; ${ }^{3}$ Department of Orthopaedic Surgery, Keio University School of \\ Medicine, Tokyo, Japan; ${ }^{4}$ Division of Orthopaedic Surgery, Chiba Cancer Center, Chiba, Japan; ${ }^{5}$ Division of \\ Musculoskeletal Tumor Surgery, Kanagawa Cancer Center, Yokohama, Japan
}

\begin{abstract}
Background. Epithelioid sarcoma (ES) is an extremely rare soft tissue sarcoma. Recently, the proximal variant has been reported to be a more aggressive subtype; however, as most reports of ES have involved small case series, the actual prognostic implications remain unclear. We investigated the clinicopathological features of patients with ES to identify the prognostic factors that influence survival.

Methods. We retrospectively analyzed the clinicopathological features of 44 patients with ES who had been treated at our institutions between 1991 and 2011. Among these patients, 26 were diagnosed histologically as having classic-type ES, whereas the remaining 18 had proximaltype ES. Thirty-three of the patients, all without distant metastases, underwent curative surgery, and the remaining 11 with distant metastases (M1) received palliative treatment.

Results. The proximal subtype was significantly correlated with a proximal tumor location, distant metastases at presentation, presence of rhabdoid cells, a higher tumor grade, and vascular invasion. The overall survival (OS) rate at 5 years for the 44 patients was $45 \%$. A superficial tumor location and lymph node metastases (N1) at presentation were independently predictive of local recurrence-free survival (LRFS), and N1 and M1 tumors were
\end{abstract}

(C) The Author(s) 2015. This article is published with open access at Springerlink.com

First Received: 12 July 2014;

Published Online: 7 February 2015

A. Kawai, $\mathrm{MD}, \mathrm{PhD}$

e-mail: akawai@ncc.go.jp independently predictive of distant metastasis-free survival and OS, respectively. The proximal subtype was associated with unfavorable LRFS and OS, although not to a statistically significant degree.

Conclusions. Proximal-type ES has significantly more aggressive clinicopathological features than classic-type ES, and lymph node or distant metastasis has the most critical impact on prognosis.

Epithelioid sarcoma (ES) is an uncommon malignant soft tissue tumor comprising approximately $1 \%$ of all soft tissue sarcomas. It is a slow-growing tumor occurring mainly in young adult males, predominantly affecting subcutaneous tissues, fasciae, or tendon sheaths of the extremities, with a predilection for the hands and forearms. $^{1-3}$

Histologically, the classic type shows a distinctive nodular, granuloma-like pattern, with spindle and epithelioid cells circumscribing areas of central degeneration and necrosis. ${ }^{4,5}$ However, a subtype of ES, the proximal type, occurs mostly in deep-seated soft tissues in the truncal region and is characterized histologically by sheets of large, atypical, epithelioid cells with vesicular nuclei and prominent nucleoli, showing a rhabdoid phenotype. ${ }^{6,7}$

Unfavorable prognostic factors for overall survival (OS) have been reported to include a proximal location. ${ }^{2,8,9}$ Recently, several authors have reported that the proximal subtype has a poor prognosis. ${ }^{6,7,9-11}$ However, as most previous reports have involved only small case series, especially with regard to proximal-type ES, the true prognostic impact of the ES subtype remains unclear., 9,12 
TABLE 1 Various clinicopathological variables in cases of classicand proximal-type epithelioid sarcoma

\begin{tabular}{|c|c|c|c|c|}
\hline Variable & Total $(n)$ & $\begin{array}{l}\text { Classic } \\
\text { type }(n)\end{array}$ & $\begin{array}{l}\text { Proximal } \\
\text { type }(n)\end{array}$ & $p$ Value \\
\hline Sex & & & & 1.000 \\
\hline Male & 30 & 18 & 12 & \\
\hline Female & 14 & 8 & 6 & \\
\hline Age at presentation (years) & & & & 0.761 \\
\hline$\leq 30$ & 16 & 10 & 6 & \\
\hline$>30$ & 28 & 16 & 12 & \\
\hline Location & & & & $<0.001$ \\
\hline Distal & 20 & 19 & 1 & \\
\hline Proximal & 24 & 7 & 17 & \\
\hline Depth $(N=43)$ & & & & 0.168 \\
\hline Superficial & 12 & 5 & 7 & \\
\hline Deep & 31 & 21 & 10 & \\
\hline Tumor size $(\mathrm{cm})(N=39)$ & & & & 0.209 \\
\hline$\leq 5$ & 22 & 15 & 7 & \\
\hline$>5$ & 17 & 8 & 9 & \\
\hline Stage $(N=30)$ & & & & 0.255 \\
\hline II & 18 & 14 & 4 & \\
\hline III & 12 & 7 & 5 & \\
\hline N0/N1 & & & & 0.093 \\
\hline No & 33 & 22 & 11 & \\
\hline N1 & 11 & 4 & 7 & \\
\hline M0/M1 & & & & 0.031 \\
\hline M0 & 33 & 23 & 10 & \\
\hline M1 & 11 & 3 & 8 & \\
\hline Rhabdoid cell & & & & 0.002 \\
\hline Not present & 20 & 17 & 3 & \\
\hline Present & 24 & 9 & 15 & \\
\hline FNCLCC grade & & & & 0.045 \\
\hline 2 & 32 & 22 & 10 & \\
\hline 3 & 12 & 4 & 8 & \\
\hline Vascular invasion & & & & 0.007 \\
\hline Not present & 32 & 23 & 9 & \\
\hline Present & 12 & 3 & 9 & \\
\hline
\end{tabular}

FNCLCC French Federation of Cancer Centers

In the present study, we therefore investigated the prognostic value of relevant clinicopathologic variables in 44 patients with ES.

\section{MATERIALS AND METHODS}

\section{Patients}

We reviewed a prospective database for four institutions (Higashi-nihon Orthopaedic and Pediatric Sarcoma Group; HOPES) covering the period from 1991 to 2011. A total of 44 patients with a confirmed diagnosis of ES made by a specialized pathologist (AY) were analyzed. The median follow-up period was 26.5 (range 1-168) months overall. All patients or their guardians provided informed consent, according to the rules approved by the respective Institutional Review Boards.

\section{Diagnostic Criteria for Each Histological Subtype}

The diagnostic criteria for ES were the same as those documented previously. ${ }^{6}$ Histologically, classic-type ES commonly presents as a multinodular proliferation of eosinophilic, epithelioid, and spindle-shaped cells. Usually, the lesion shows minimal cytologic atypia, with vesicular nuclei and often single and central nucleoli. Occasionally, the epithelioid cells may have a rhabdoid appearance, and tumor nodules may frequently undergo central necrosis, resulting in a pattern resembling a benign necrobiotic granulomatous process. Proximal-type ES is characterized by a predominantly large epithelioid cytomorphology, marked cytologic atypia, frequent occurrence of rhabdoid features, and lack of a granuloma-like pattern in most cases. ES with hybrid features of both classic and proximal-type ES is grouped as proximal-type ES.

\section{Study Parameters}

At the time of diagnosis, local tumor extent was assessed using computed tomography (CT) and/or magnetic resonance imaging (MRI). Lymph node and/or distant metastasis before treatment was assessed using enhanced CT and/or whole-body positron emission tomography (PET)-CT. Tumor location in the distal extremity was defined as 'distal', and localization in the proximal extremity or axial trunk was defined as 'proximal'. Disease stage was classified using the American Joint Committee on Cancer/International Union Against Cancer TNM staging system version 7 (AJCC stage). ${ }^{13}$ Histological grade was assessed using the French Federation of Cancer Centers (FNCLCC) grading system. ${ }^{14}$

\section{Treatment}

Thirty-three patients without distant metastasis at presentation (M0) underwent surgical treatment of the primary tumor with curative intent, which comprised wide resection in 14 patients, additional wide resection in 9 patients, and amputation in 10 patients. Regional lymphadenectomy was performed in 12 patients who had regional lymph node swelling. Six of these 12 patients were found to have regional lymph node metastases, and the remaining 6 were found to be negative after histological examination. The surgical margins were microscopically negative in $24(73 \%)$ patients, positive in $8(24 \%)$ patients, and not available (NA) in one 
TABLE 2 Univariate and multivariate analysis of factors influencing local recurrence-free survival in 33 patients with M0 tumors

\begin{tabular}{|c|c|c|c|c|c|c|c|}
\hline \multirow[t]{2}{*}{ Variable } & \multirow[t]{2}{*}{ No. of cases } & \multicolumn{3}{|l|}{ Univariate analysis } & \multicolumn{3}{|c|}{ Multivariate analysis } \\
\hline & & 2-year LRFS rate & 5-year LRFS rate & $p$-Value & HR & $95 \% \mathrm{CI}$ & $p$ Value \\
\hline Sex & & & & 0.348 & & & \\
\hline Male & 24 & 83.1 & 69.3 & & & & \\
\hline Female & 9 & 77.8 & 46.7 & & & & \\
\hline Age at presentation (years) & & & & 0.838 & & & \\
\hline$\leq 30$ & 11 & 72.7 & 72.7 & & & & \\
\hline$>30$ & 22 & 86.4 & 57.6 & & & & \\
\hline Location & & & & 0.020 & & & NS \\
\hline Distal & 18 & 100 & 75.0 & & & & \\
\hline Proximal & 15 & 58.7 & 46.9 & & & & \\
\hline Depth & & & & 0.026 & 0.260 & $0.072-0.941$ & 0.040 \\
\hline Superficial & 11 & 54.5 & 43.6 & & & & \\
\hline Deep & 22 & 95.2 & 71.4 & & & & \\
\hline Tumor size $(\mathrm{cm})(N=30)$ & & & & 0.425 & & & \\
\hline$\leq 5$ & 20 & 75 & 60.0 & & & & \\
\hline$>5$ & 10 & 88.9 & 71.1 & & & & \\
\hline Stage $(N=30)$ & & & & 0.168 & & & \\
\hline II & 18 & 88.9 & 72.7 & & & & \\
\hline III & 12 & 64.8 & 48.6 & & & & \\
\hline N0/N1 & & & & 0.005 & 5.714 & $1.436-22.739$ & 0.013 \\
\hline No & 27 & 92.6 & 69.4 & & & & \\
\hline N1 & 6 & 33.3 & NA & & & & \\
\hline Morphological subtype & & & & 0.052 & & & \\
\hline Classic type & 23 & 91.3 & 70.2 & & & & \\
\hline Proximal type & 10 & 58.3 & 43.8 & & & & \\
\hline FNCLCC grade & & & & 0.265 & & & \\
\hline 2 & 27 & 85 & 66.8 & & & & \\
\hline 3 & 6 & 66.7 & 44.4 & & & & \\
\hline Surgical margin $(N=32)$ & & & & 0.036 & & & NS \\
\hline Negative & 24 & 87.5 & 74.0 & & & & \\
\hline Positive & 8 & 62.5 & 31.3 & & & & \\
\hline Adjuvant radiotherapy & & & & 0.547 & & & \\
\hline Done & 6 & 83.3 & 83.3 & & & & \\
\hline Not done & 27 & 81.3 & 59.6 & & & & \\
\hline Adjuvant chemotherapy & & & & 0.201 & & & \\
\hline Done & 3 & 100 & 100 & & & & \\
\hline Not done & 30 & 79.7 & 57.0 & & & & \\
\hline
\end{tabular}

$N S$ not significant, $H R$ hazard ratios, $95 \%$ CI $95 \%$ confidence interval

patient. Adjuvant therapy included preoperative radiotherapy in 2 patients $(6 \%)$, postoperative radiotherapy in 4 (12\%) patients, pre-/postoperative systemic anthracyclinebased chemotherapy in 1 patients $(3 \%)$, and postoperative chemotherapy in 2 patients $(6 \%)$.

Eleven patients $(25 \%)$ with distant metastasis at presentation (M1) received palliative treatment with various types of chemotherapy consisting of doxorubicin and/or ifosfamide, radiotherapy, and/or surgery.

\section{Statistical Analysis}

In order to compare the differences in clinicopathological features between classic- and proximal-type ES, the $\chi^{2}$ test was employed. Local recurrence-free survival (LRFS), distant metastasis-free survival (DMFS), and OS were calculated from the clinical databases using the KaplanMeier method. Patients with M0 tumors were evaluated for LRFS, DMFS, and OS from the date of definitive surgery 

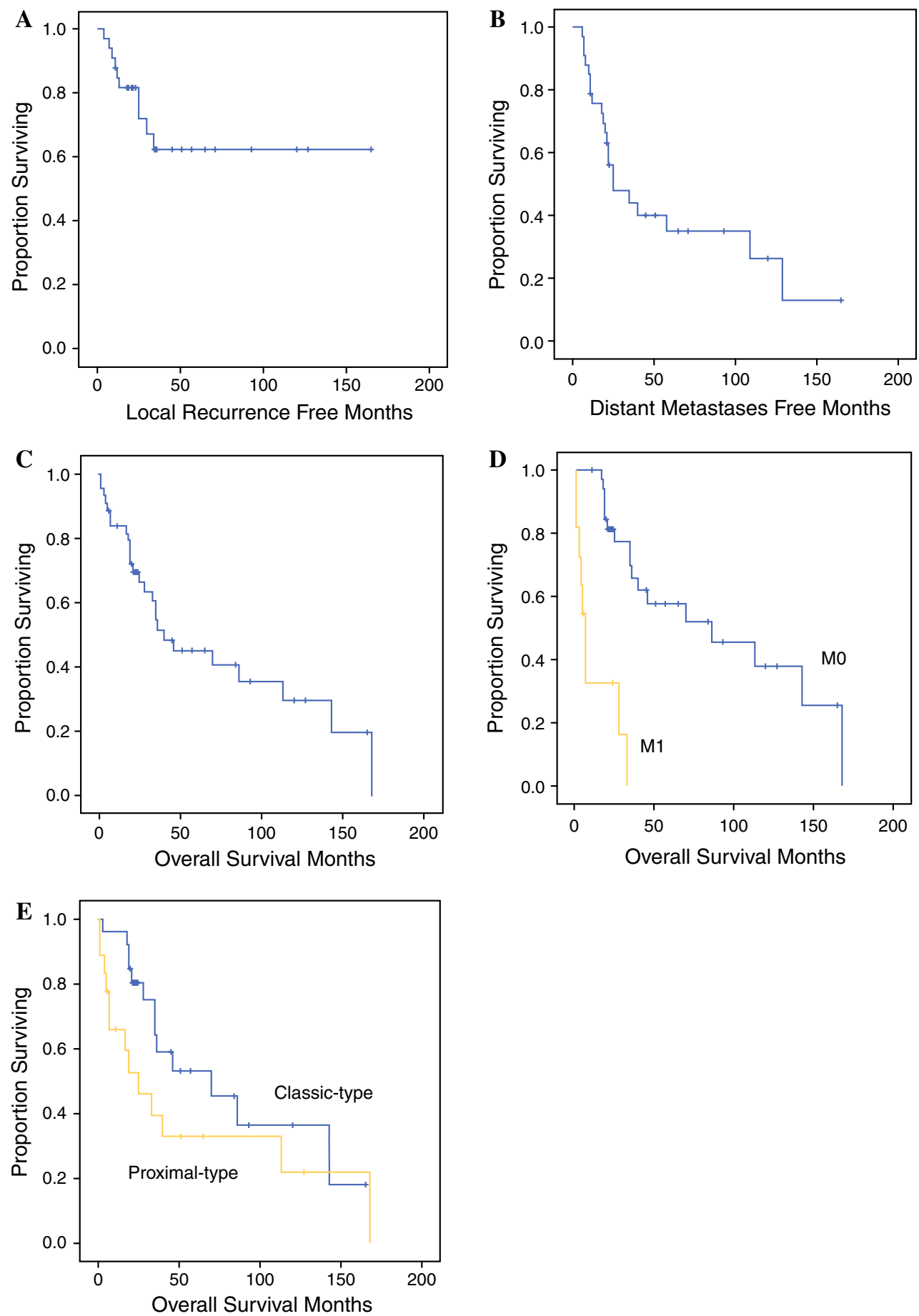

FIG. 1 a Local recurrence-free survival rates for the 33 patients with M0 tumors were 82 and $62 \%$ at 2 and 5 years, respectively. b Distant metastases-free survival rates at 2 and 5 years were 56 and $35 \%$, respectively. c Overall survival rates for the 44 patients overall were 70 and $45 \%$ at 2 and 5 years, respectively. d Overall survival rates for the 33 patients with M0 tumors were 81 and $57 \%$ at 2 and

until the most recent follow-up, recurrence, or death. All patients were evaluated for OS from the date of diagnosis at our institutions until the most recent follow-up or death. The
5 years, respectively, and those for the 11 patients with M1 tumors were 33 and $0 \%$, respectively $(p<0.001)$. e Overall survival rates for the 26 patients with classic-type epithelioid sarcoma were 81 and $53 \%$ at 2 and 5 years, respectively, and those for the 18 patients with proximal-type epithelioid sarcoma were 53 and $33 \%$, respectively $(p=0.124)$

log-rank test was used to compare the survival curves for the different subgroups of patients to establish the potential prognostic value of various factors. Stepwise multivariate 
Cox regression analyses were performed to identify prognostic factors that were significant. Prognostic factors with statistical significance $(p<0.05)$ in the univariate analysis were included in the multivariate analysis. Statistical analysis was performed using the PASW statistics 18 package (SPSS Inc., Chicago, IL, USA).

\section{RESULTS}

\section{Clinical Features}

Thirty patients $(68 \%)$ were male and $14(32 \%)$ were female. The median age at the first visit to our hospitals was 37 (range 6-69) years. Twenty tumors (46\%) were located in distal extremities (forearm, seven; hand, four; finger, five; lower leg, one; foot, three), eight (18\%) in proximal extremities (upper arm, one; axilla, two; buttock, two; thigh, three) and $16(36 \%)$ in the trunk (paravertebral region, two; back, two; abdominal wall, two; inguinal region, five; perineum, five;). Thirty-one tumors (70\%) were deep-seated, $12(27 \%)$ were superficial, and $1(3 \%)$ was not evaluable. Seven of 12 superficial tumors occurred in the inguinal or perineal region. The median tumor size was 5 (range 1-17) $\mathrm{cm} ; 25$ lesions $(57 \%)$ were primary, whereas $19(43 \%)$ were recurrent. On the basis of AJCC staging, 18 cases were stage II, 12 were stage III (including 6 with N1M0), 11 were stage IV (5 with N1M1), and 3 were not evaluable.

\section{Histological Features}

FNCLCC grade was assessed in all 44 cases: 32 cases (73\%) were grade 2, and the remaining $12(27 \%)$ were grade 3. Twenty-eight cases (64\%) had hemorrhage, 12 $(27 \%)$ had vascular invasion, $6(14 \%)$ had perineural invasion, and $6(14 \%)$ had reactive bone formation.

Immunohistochemical studies showed that pan cytokeratin AE1/AE3 reactivity was present in all 44 cases. CD34 was positive in $28(74 \%)$ of 38 cases that were examined, and S-100 was minimally positive in $4(14 \%)$ of 24 cases that were examined. Loss of expression of INI1 was evident in all $(100 \%)$ of the 29 cases where this was examined.

Twenty-six cases $(60 \%)$ were diagnosed as classic-type ES and $18(40 \%)$ were diagnosed as proximal-type ES. Comparisons between the two histologic types revealed that the proximal type was significantly correlated with a proximal location $(p<0.001)$, distant metastasis at presentation [M1] $(p=0.031)$, presence of rhabdoid cells $(p=0.002)$, a higher tumor grade $(p=0.045)$, and vascular invasion $(p=0.007)$ (Table 1$)$. Proximal-type ES also showed a higher incidence of N1 disease (proximaltype $39 \%$ vs. classic-type $15 \%$ ), although statistically this was not significant $(p=0.093)$ (Table 1).

\section{Local Recurrence}

Among the 33 patients with M0 tumors who underwent curative surgery, local recurrences were noted in 10 (30\%). The LRFS rates at 2 and 5 years were 82 and $62 \%$, respectively (Fig. 1a). The median interval from surgery until the first local recurrence was 25 (range 4-165) months. Three of these ten patients developed both local recurrence and distant metastasis simultaneously.

Univariate analysis showed that a proximal tumor location $(p=0.020)$, superficial localization $(p=0.026)$, lymph node metastasis at presentation $(\mathrm{N} 1)(p=0.005)$, and a positive surgical margin $(p=0.036)$ were all correlated with LRFS. There was a tendency $(p=0.052)$ for an increased incidence of local recurrence in proximal-type ES relative to classic-type ES. Multivariate analysis showed that tumor depth $(p=0.040)$ and lymph node metastasis $(p=0.013)$ remained independent prognostic factors for LRFS (Table 2).

\section{Distant Metastasis}

Distant metastases occurred in $32(73 \%)$ patients. The sites of metastasis at initial presentation included distant lymph nodes in 13 patients, the lung in 12 patients, lymph nodes and lungs in 4 patients, lung and muscle in 1 patient, the lung, liver and scalp in 1 patient, and bone in 1 patient.

Twenty-one $(64 \%)$ of the 33 patients with M0 tumors developed metastasis after a median period of 20 (range 6-122) months. The DMFS rates for these patients after 2 and 5 years were 56 and $35 \%$, respectively (Fig. 1b). Univariate analysis showed that only lymph node metastasis at presentation $(p=0.003)$ was a significant prognostic factor for DMFS, and this remained significant after multivariate analysis $(p=0.005)$ (Table 3).

\section{Overall Survival}

At the final follow-up, 14 (32\%) patients were alive without disease, 4 (9\%) were alive with disease, and 26 (59\%) had died of disease. OS at 2 and 5 years was 70 and $45 \%$, respectively (Fig. 1c). Univariate analysis showed that AJCC stage $(p<0.001)$, lymph node metastasis at presentation $(p=0.008)$, distant metastasis at presentation $(p<0.001)$, and histological grade $(p=0.019)$ were significant prognostic factors for OS. Multivariate analysis identified only distant metastasis at presentation as a significant prognostic factor $(p<0.001)$ (Table 4; Fig. 1d).

At 2 and 5 years, the OS of the 18 patients with proximal-type ES was 53 and $33 \%$, respectively. This was worse than the OS of the 26 patients with classic-type ES, i.e. 81 and $53 \%$, respectively (Fig. 1e). 
TABLE 3 Univariate and multivariate analysis of factors influencing distant metastases-free survival in 33 patients with M0 tumors

\begin{tabular}{|c|c|c|c|c|c|c|c|}
\hline \multirow[t]{2}{*}{ Variable } & \multirow[t]{2}{*}{ No. of cases } & \multicolumn{3}{|l|}{ Univariate analysis } & \multicolumn{3}{|c|}{ Multivariate analysis } \\
\hline & & 2-year DMFS rate & 5-year DMFS rate & $p$ Value & HR & $95 \% \mathrm{CI}$ & $p$ Value \\
\hline Sex & & & & 0.321 & & & \\
\hline Male & 24 & 42.6 & 37.3 & & & & \\
\hline Female & 9 & 77.8 & 31.1 & & & & \\
\hline Age at presentation, years & & & & 0.847 & & & \\
\hline$\leq 30$ & 11 & 45.5 & 34.1 & & & & \\
\hline$>30$ & 22 & 61.8 & 34.6 & & & & \\
\hline Location & & & & 0.972 & & & \\
\hline Distal & 18 & 54.5 & 29.2 & & & & \\
\hline Proximal & 15 & 58.2 & 41.6 & & & & \\
\hline Depth & & & & 0.906 & & & \\
\hline Superficial & 11 & 45.5 & 36.4 & & & & \\
\hline Deep & 22 & 61.2 & 32.6 & & & & \\
\hline Tumor size $(\mathrm{cm})(N=30)$ & & & & 0.708 & & & \\
\hline$\leq 5$ & 20 & 50.0 & 31.2 & & & & \\
\hline$>5$ & 10 & 56.3 & 42.2 & & & & \\
\hline Stage $(N=30)$ & & & & 0.255 & & & \\
\hline II & 18 & 55.6 & 41.7 & & & & \\
\hline III & 12 & 46.9 & 23.4 & & & & \\
\hline $\mathrm{N} 0 / \mathrm{N} 1$ & & & & 0.003 & 4.101 & $1.508-11.155$ & 0.006 \\
\hline No & 27 & 64.9 & 43.7 & & & & \\
\hline N1 & 6 & 16.7 & 0 & & & & \\
\hline Morphological subtype & & & & 0.937 & & & \\
\hline Classic type & 23 & 55.2 & 29.4 & & & & \\
\hline Proximal type & 10 & 57.1 & 45.7 & & & & \\
\hline FNCLCC grade & & & & 0.296 & & & \\
\hline 2 & 27 & 61.3 & 39.4 & & & & \\
\hline 3 & 6 & 33.3 & 16.7 & & & & \\
\hline Surgical margin $(N=32)$ & & & & 0.231 & & & \\
\hline Negative & 24 & 56.7 & 45.4 & & & & \\
\hline Positive & 8 & 50.0 & 12.5 & & & & \\
\hline Adjuvant radiotherapy & & & & 0.769 & & & \\
\hline Done & 6 & 57.8 & 32.1 & & & & \\
\hline Not done & 27 & 50.0 & 50.0 & & & & \\
\hline Adjuvant chemotherapy & & & & 0.239 & & & \\
\hline Done & 3 & 54.8 & 31.3 & & & & \\
\hline Not done & 30 & 66.7 & 66.7 & & & & \\
\hline Local recurrence & & & & 0.149 & & & \\
\hline Not occurred & 23 & 53.7 & 53.7 & & & & \\
\hline Occurred & 10 & 60.0 & 10.0 & & & & \\
\hline
\end{tabular}

NS not significant, $H R$ hazard ratios, $95 \%$ CI $95 \%$ confidence interval

\section{DISCUSSION}

ES is an aggressive but rare soft tissue tumor with severe consequences, even with currently available multimodal therapy. Risk factors for OS of ES patients have been reported to be large tumor size, ${ }^{2,15-17}$ deep-seated occurrence, ${ }^{2,15,18}$ proximal location, ${ }^{2,8,9}$ local recurrence, ${ }^{15,18}$ lymph node involvement, ${ }^{2,10,18}$ mitosis, necrosis, hemorrhage and vascular invasion. ${ }^{2,16,19}$ However, because of the rarity of ES, few data on its clinical behavior or the survival of affected patients are available. Recently, the proximal subtype of ES has been reported to have a poorer prognosis than the classical 
TABLE 4 Univariate and multivariate analysis of factors influencing overall survival of all 44 patients with epithelioid sarcoma

\begin{tabular}{|c|c|c|c|c|c|c|c|}
\hline \multirow[t]{2}{*}{ Variable } & \multirow[t]{2}{*}{ No. of cases } & \multicolumn{3}{|c|}{ Univariate analysis } & \multicolumn{3}{|c|}{ Multivariate analysis } \\
\hline & & 2-year OS rate & 5 -year OS rate & $p$ Value & HR & $95 \% \mathrm{CI}$ & $p$ Value \\
\hline \multicolumn{4}{|l|}{ Sex } & 0.410 & & & \\
\hline Male & 30 & 68.1 & 50.0 & & & & \\
\hline Female & 14 & 71.4 & 35.7 & & & & \\
\hline \multicolumn{4}{|c|}{ Age at presentation (years) } & 0.704 & & & \\
\hline$\leq 30$ & 16 & 73.7 & 36.8 & & & & \\
\hline$>30$ & 28 & 67.0 & 51.0 & & & & \\
\hline \multicolumn{4}{|l|}{ Location } & 0.289 & & & \\
\hline Distal & 20 & 80.0 & 52.5 & & & & \\
\hline Proximal & 24 & 60.7 & 38.7 & & & & \\
\hline \multicolumn{4}{|l|}{ Depth $(N=43)$} & 0.893 & & & \\
\hline Superficial & 12 & 66.7 & 33.3 & & & & \\
\hline Deep & 31 & 73.1 & 53.6 & & & & \\
\hline \multicolumn{4}{|c|}{ Tumor size $(\mathrm{cm})(N=39)$} & 0.335 & & & \\
\hline$\leq 5$ & 22 & 72.7 & 46.2 & & & & \\
\hline$>5$ & 17 & 63.1 & 36.1 & & & & \\
\hline \multicolumn{4}{|l|}{ Stage $(N=41)$} & $<0.001$ & & & NS \\
\hline II & 18 & 83.3 & 57.0 & & & & \\
\hline III & 12 & 72.7 & 48.5 & & & & \\
\hline IV & 11 & 32.7 & 0 & & & & \\
\hline \multicolumn{4}{|l|}{$\mathrm{N} 0 / 1$} & 0.008 & & & NS \\
\hline No & 33 & 78.0 & 57.2 & & & & \\
\hline N1 & 11 & 45.5 & 11.4 & & & & \\
\hline \multicolumn{4}{|l|}{ M0/1 } & $<0.001$ & 8.570 & $3.094-23.736$ & $<0.001$ \\
\hline M0 & 33 & 81.1 & 57.7 & & & & \\
\hline M1 & 11 & 32.7 & 0 & & & & \\
\hline \multicolumn{4}{|c|}{ Morphological subtype } & 0.124 & & & \\
\hline Classic type & 26 & 80.6 & 53.2 & & & & \\
\hline Proximal type & 18 & 52.6 & 32.9 & & & & \\
\hline \multicolumn{4}{|l|}{ FNCLCC grade } & 0.019 & & & NS \\
\hline 2 & 32 & 74.3 & 56.5 & & & & \\
\hline 3 & 12 & 56.2 & 18.7 & & & & \\
\hline \multicolumn{4}{|c|}{ Surgical margin $(N=32)$} & 0.396 & & & \\
\hline Negative & 24 & 78.3 & 56.9 & & & & \\
\hline Positive & 8 & 87.5 & 58.3 & & & & \\
\hline \multicolumn{4}{|c|}{ Adjuvant radiotherapy $(N=33)$} & 0.704 & & & \\
\hline Done & 6 & 83.3 & 55.6 & & & & \\
\hline Not done & 27 & 80.8 & 58.0 & & & & \\
\hline \multicolumn{4}{|c|}{ Adjuvant chemotherapy $(N=33)$} & 0.414 & & & \\
\hline Done & 3 & 66.7 & 66.7 & & & & \\
\hline Not done & 30 & 79.2 & 57.2 & & & & \\
\hline \multicolumn{4}{|c|}{ Local recurrence $(N=33)$} & 0.147 & & & \\
\hline Not occurred & 23 & 81.6 & 62.7 & & & & \\
\hline Occurred & 10 & 80.0 & 50.0 & & & & \\
\hline
\end{tabular}

NS not significant, $H R$ hazard ratios, $95 \%$ CI $95 \%$ confidence interval 
type. ${ }^{6,7,9-11}$ Rekhi et al. reported that proximal-type ES included a slightly higher proportion of M1 tumors (43\%) than classic-type ES (35\%), although the difference was not statistically significant $(p=0.61) .{ }^{10}$ In our present study of ES, the proximal type included a significantly higher proportion of M1 tumors (44\%) than the classic type (12\%) $(p=0.015)$ and tended to have a higher proportion of $\mathrm{N} 1$ tumors $(39 \%)$ than the classic type $(15 \%)$, although the difference was not statistically significant $(p=0.093)$.

It has been reported previously that $65-80 \%$ of ES cases were classified as FNCLCC grade 2 tumors and 20-35\% as grade 3 tumors. ${ }^{9,10}$ In addition, it has been reported that proximal-type ES included a higher proportion of grade 3 cases (64-73\%). ${ }^{9,10}$ In addition, in our present study the proximal subtype included a significantly higher proportion of higher-grade tumors (67\%; $p=0.045)$. Histologically, proximal-type ES frequently shows rhabdoid features. 6,7 Hasegawa et al. revealed that $14(70 \%)$ of 20 cases of proximal-type ES contained rhabdoid cells. ${ }^{7}$ We also observed a higher percentage of rhabdoid cells in proximal-type ES $(83 \%)$ than in classictype $(35 \%)$ ES $(p=0.002)$. Proximal-type ES also showed a significantly higher rate of vascular invasion $(50 \%)$ than classic-type ES $(13 \%)(p=0.007)$. To our knowledge, no previous report has mentioned the incidence of vascular invasion associated with ES subtypes. These results indicate that proximal-type ES has a more histologically aggressive nature than classic-type ES.

Deep-seated tumor localization has been reported to be an independent risk factor influencing LRFS. ${ }^{12}$ In our present study, a superficial location and lymph node metastasis were independent risk factors for local recurrence. Although this contrasts with previous reports, our finding could be explained by the higher number of superficial tumors in surgically more challenging sites, such as the perineal and inguinal regions, compared with other case series. ${ }^{6,7}$ In-transit metastasis is defined as a type of metastasis in which cancer spreads through a lymph vessel and begins to grow more than $2 \mathrm{~cm}$ away from the primary tumor before it reaches the nearest lymph node. ${ }^{20}$ Although in-transit metastasis has not been reported in ES, it may play a role in inducing local recurrence in soft tissue sarcomas, especially when there is a high potential for lymph node metastasis. This mechanism could explain the higher rate of local recurrence of $\mathrm{N} 1$ tumors in our present series.

ES has been reported to have a high rate of distant metastasis ranging from 40 to $57 \% .^{12,15-18,21}$ The rate of $73 \%$ recorded in the present study is higher than in previous reports; however, this could have been because a substantial number of cases in our series were either at a high tumor stage (N1 or M1 tumors, 39\%) or were recurrent cases $(43 \%)$ at initial presentation. ${ }^{12,18,22}$ The most common initial sites of distant metastasis in our series were the lung (45\%) and distant lymph nodes (43\%). Independent risk factors for DMFS have been reported to be large tumor size, ${ }^{22}$ deep-seated location, ${ }^{18}$ local recurrence, and regional lymph node metastasis. ${ }^{12,18}$ In our present series, the presence of lymph node metastasis was the only independent risk factor for DMFS.

The OS rates at 5 years for ES have been reported to be $32-78 \% .^{12,15-18,21}$ In our series, the OS rate at 5 years (45\%) was relatively low but within the previously described range. We found that distant metastasis was the only independent factor predictive of a poor outcome. This would likely have been due to the limited number of ES patients, as well as the relatively short follow-up period (median 26.5 months).

It is still debatable whether prophylactic lymph node dissection is beneficial for ES patients. ${ }^{12,15,17,21-23}$ In the present study, lymph node dissection was indicated only when lymph node involvement was observed by diagnostic imaging. As lymphatic relapse was the most critical factor associated with poor outcome in both types of ES, it will be necessary to improve the detection and treatment of such lymphatic spread. Currently, we perform PET-CT examinations on all ES patients, and if lymph node involvement is suspected, we perform serial lymph node dissection and adjuvant radiation therapy if the resected node is histologically positive.

\section{CONCLUSIONS}

We found that proximal-type ES had significantly higher clinicopathological aggressiveness than classic-type ES, and was associated with a proximal tumor location, a higher tumor stage, presence of rhabdoid cells, a higher tumor grade, and vascular invasion. Lymph node and distant metastases had the most critical impact on prognosis. Taking the rarity of this tumor into consideration, the number of patients in our series might have been too small to allow any definitive conclusion to be drawn. Therefore, further validation using an independent cohort of patients with ES is needed. Despite its slow growth, ES can be extremely aggressive when disseminated, and currently no useful treatments are available. Novel strategies are therefore needed to improve the survival of patients with these highly aggressive sarcomas.

ACKNOWLEDGMENT The authors would like to thank Masahiro Gomi for helpful discussion regarding statistics. This work was supported by a Japan Society for the Promotion of Science (JSPS) Grant-in-Aid for Scientific Research (Grant number 26293342) to Akira Kawai.

CONFLICT OF INTEREST Naofumi Asano, Akihiko Yoshida, Koichi Ogura, Eisuke Kobayashi, Michiro Susa, Hideo Morioka, Shintaro Iwata, Takeshi Ishii, Toru Hiruma, Hirokazu Chuman, and Akira Kawai have no conflicts of interest to declare. 
OPEN ACCESS This article is distributed under the terms of the Creative Commons Attribution License which permits any use, distribution, and reproduction in any medium, provided the original author(s) and the source are credited.

\section{REFERENCES}

1. Enzinger FM. Epithelioid sarcoma: a sarcoma simulating a granuloma or a carcinoma. Cancer. 1970;26:1029-41.

2. Chase DR, Enzinger FM. Epithelioid sarcoma: diagnosis, prognostic indicators, and treatment. Am J Surg Pathol. 1985;9:241-63.

3. Evans HL, Baer SC. Epithelioid sarcoma: a clinicopathologic and prognostic study of 26 cases. Semin Diagn Pathol. 1993;10:286-91.

4. Miettinen M, Fanburg-Smith JC, Virolainen M, Shmookler BM, Fetsch JF. Epithelioid sarcoma: an immunohistochemical analysis of 112 classical and variant cases and a discussion of the differential diagnosis. Hum Pathol. 1999;30:934-42.

5. Schmidt D, Harms D. Epithelioid sarcoma in children and adolescents: an immunohistochemical study. Virchows Arch A Pathol Anat Histopathol. 1987;410:423-31.

6. Guillou L, Wadden C, Coindre JM, Krausz T, Fletcher CD. "Proximal-type" epithelioid sarcoma, a distinctive aggressive neoplasm showing rhabdoid features: clinicopathologic, immunohistochemical, and ultrastructural study of a series. Am J Surg Pathol. 1997;21:130-46.

7. Hasegawa T, Matsuno Y, Shimoda T, Umeda T, Yokoyama R, Hirohashi S. Proximal-type epithelioid sarcoma: a clinicopathologic study of 20 cases. Mod Pathol. 2001;14:655-63.

8. Livi L, Shah N, Paiar F, et al. Treatment of epithelioid sarcoma at the royal marsden hospital. Sarcoma. 2003;7:149-52.

9. Casanova M, Ferrari A, Collini P, et al. Epithelioid sarcoma in children and adolescents: a report from the Italian Soft Tissue Sarcoma Committee. Cancer. 2006;106:708-17.

10. Rekhi B, Gorad BD, Chinoy RF. Clinicopathological features with outcomes of a series of conventional and proximal-type epithelioid sarcomas, diagnosed over a period of 10 years at a tertiary cancer hospital in India. Virchows Arch. 2008;453:141-53.
11. Gasparini P, Facchinetti F, Boeri M, et al. Prognostic determinants in epithelioid sarcoma. Eur J Cancer. 2011;47:287-95.

12. Baratti D, Pennacchioli E, Casali PG, et al. Epithelioid sarcoma: prognostic factors and survival in a series of patients treated at a single institution. Ann Surg Oncol. 2007;14:3542-51.

13. Edge SB, Compton CC. The American Joint Committee on Cancer: the 7th edition of the AJCC cancer staging manual and the future of TNM. Ann Surg Oncol. 2010;17:1471-4.

14. Trojani M, Contesso G, Coindre JM, et al. Soft-tissue sarcomas of adults: study of pathological prognostic variables and definition of a histopathological grading system. Int J Cancer. 1984;33:37-42.

15. Bos GD, Pritchard DJ, Reiman HM, Dobyns JH, Ilstrup DM, Landon GC. Epithelioid sarcoma: an analysis of fifty-one cases. $J$ Bone Joint Surg Am. 1988;70:862-70.

16. Halling AC, Wollan PC, Pritchard DJ, Vlasak R, Nascimento AG. Epithelioid sarcoma: a clinicopathologic review of 55 cases. Mayo Clin Proc. 1996;71:636-42.

17. de Visscher SA, van Ginkel RJ, Wobbes T, et al. Epithelioid sarcoma: still an only surgically curable disease. Cancer. 2006;107:606-12.

18. Spillane AJ, Thomas JM, Fisher C. Epithelioid sarcoma: the clinicopathological complexities of this rare soft tissue sarcoma. Ann Surg Oncol. 2000;7:218-25.

19. Chbani L, Guillou L, Terrier P, et al. Epithelioid sarcoma: a clinicopathologic and immunohistochemical analysis of 106 cases from the French sarcoma group. Am J Clin Pathol. 2009;131:222-7.

20. Zbytek B, Carlson JA, Granese J, Ross J, Mihm MC Jr, Slominski A. Current concepts of metastasis in melanoma. Expert Rev Dermatol. 2008;3:569-85.

21. Ross HM, Lewis JJ, Woodruff JM, Brennan MF. Epithelioid sarcoma: clinical behavior and prognostic factors of survival. Ann Surg Oncol. 1997;4:491-5.

22. Callister MD, Ballo MT, Pisters PW, et al. Epithelioid sarcoma: results of conservative surgery and radiotherapy. Int $J$ Radiat Oncol Biol Phys. 2001;51:384-91.

23. Herr MJ, Harmsen WS, Amadio PC, Scully SP. Epithelioid sarcoma of the hand. Clin Orthop Relat Res. 2005;(431):193-200. 